\title{
Clonic Convulsion
}

National Cancer Institute

\section{Source}

National Cancer Institute. Clonic Convulsion. NCI Thesaurus. Code C50496.

A convulsion marked by alternating contracting and relaxing of the muscles. 